\title{
ÇÜTAD
}

Çukurova Üniversitesi Türkoloji

Araștırmaları Dergisi

Cilt 2, Sayı 2

Aralık 2017

Geliş Tarihi: 14.11.2017

Kabul Tarihi: 25.12.2017

\section{TÜRKÇEDE RENKLERİ TANIMLAMA \\ SORUNU}

\section{ÖZET}

\section{Mehmet ÖZMEN $^{1}$}

Tamamen soyut olan renkler, doğrudan doğruya tanımlanamaz. Fizik biliminin olanaklarına göre, dalga boyu ve yansıma olayı olarak tanımlanmak da ölçünlü dilde kullanılan bir yöntem değildir. Renkler, nesnelerin, bitkilerin, renklerinden; bir rengin açıklı veya koyuluğundan $v b$. değişik yöntemlerden yararlanmak suretiyle tanımlanır. Ölçünlü dilde yer alan renk adları yanında ölçünlü dilde yer almayan binlerce rengin tanımında da farklı güçlüklerle karşılaşılmaktadır. $\mathrm{Bu}$ güçlük, renklerin her türlüsü için geçerlidir. Doğada bulunan veya sanayide üretilen binlerce renk ile ara renklerin tümünü tanımlamak mümkün değildir. Olsa olsa, bunların belli başlılarını tanımlayabiliriz.

Anahtar kelimeler: Renkler, tanım, tanımlama, ana renk, ara renk, doğa.

\section{THE PROBLEM OF DEFINING COLORS IN TURKISH}

\begin{abstract}
Colors completely abstract cannot directly be defined. In respect to means of physics, also being identified as wavelength and reflection is also not a method used in figurative language. Colors could thereby be defined by the colors of objects, plants; by the clarity and
\end{abstract}

${ }^{1}$ Çukurova Üniversitesi Fen-Edebiyat Fakültesi Türk Dili ve Edebiyatı Bölümü, Prof. Dr. mehmet_ozmen01@hotmail.com; ozmen@cu.edu.tr 


\section{ÇÜTAD}

\section{Çukurova Üniversitesi Türkoloji}

Araștırmaları Dergisi

Cilt 2, Sayı 2

Aralık 2017

depth of shade and also benefiting from different methods. Various difficulties are encountered while defining thousands of colors not only in standard but also in nonstandard language. This difficulty applies to all kinds of colors. It is not possible to define thousands of colors existing in nature or produced by industry as well as all kinds of accent colors. At the utmost, we could define the major ones.

Key words: Colours, definition, to define, primary colour, accent colour, nature.

\section{GÍRIŞ̧}

Tamamen soyut olan renkler, doğrudan doğruya tanımlanamaz. Fizik biliminin olanaklarına göre, dalga boyu ve yansıma olayı olarak tanımlanmak da ölçünlü dilde kullanılan bir yöntem değildir. Türkçe Sözlük'te², renk kelimesi, "Cisimler tarafından yansılanan 1şı̆̆ın gözde oluşturduğu duyum.” biçiminde tanımlanmıştır; ama hiçbir renk, ölçünlü dilde bu ölçülere göre tanımlanmaz.

\section{RENKLERİ TANIMLAMA YÖNTEMLERİ}

Doğasındaki özellikler dolayısıyla doğrudan doğruya tanımlanamayan renkler, dolaylı olarak, nesne, meyve veya bitki renklerinden aktarmalar yapılarak, karşıt renklerden, benzetmelerden, eş anlamlardan, zit anlamlardan, açıklık, koyuluk veya bir renge yakınlıklardan yaralanarak, kıyaslamalar yapılarak tanımlanabilmektedir.

${ }^{2} \mathrm{Bu}$ incelemedeki renk tanımlamaları için "Türkçe Sözlük 11. Baskı, Türk Dil Kurumu Yayınları: 549, Ankara.” esas alınmıştır. Bundan sonra Türkçe Sözlük için TS kısaltması kullanılacaktır. 


\section{ÇÜTAD}

\section{Çukurova Üniversitesi Türkoloji}

Araştırmaları Dergisi

Cilt 2, Sayı 2

Aralık 2017

\subsection{Karşıt renklerle tanımlanan renkler}

Birbirlerinin karşıtı durumunda olan beyaz / ak, siyah / kara renklerinin tanımı, nesne renklerinden aktarmalarla ve karşıtlıkları ölçü alınarak yapılmaktadır. Elbette, bazı renk tanımlarında da olduğu gibi, tanımlanan rengin bilinmesi için, karşıt renk ile renginden aktarma yapılan nesnenin bilinmesi gerekir:

ak: kar, süt, vb. rengi, beyaz, kara ve siyah karşıtı ${ }^{3}$.

beyaz: Ak, kara, siyah karşıtt.

kara: En koyu renk, siyah, ak, beyaz, karşıtt. 2. Esmer.

siyah: Kara, ak, beyaz karşıtt.

$\mathrm{Bu}$ tanımlara göre ak rengin ne olduğunu anlatabilmek için karın ve sütün renginden, kara, siyah karşıtlı̆̆ından, kara rengin tanımı için de karşıtı olan $a k$ / beyaz renkten ve rengin diğer renklere oranla koyuluğundan yararlanılmıştır.

Aynı durumu İngilizcede de görüyoruz. İngilizcede de ak/beyaz, kara/siyah renkleri, nesne renklerinden aktarılarak veya karşıtlarıyla kıyaslanarak tanımlanmaktadır.

black 1. Without light or almost without light; the colour of this printing-ink; opposite to white. (...) (Hornby-Gatenby-Wakefield: 1963).

black: 1. Destitute of light, or incapable of reflecting it; of the color of soot or

coal; of the darkest or a very dark color, the opposite of white; characterized by such a color; as, black cloth; black hair or eyes. (...).

(http://www.webster-dictionary.org/definition/black. 24.05.2016).

${ }^{3}$ Atıfta bulunulmayan tanımlar, TS'ten alınmıştır. 


\section{ÇÜTAD}

\section{Çukurova Üniversitesi Türkoloji}

Araștırmaları Dergisi

Cilt 2, Sayı 2

Aralık 2017

white: 1, of the colour of fresh snow or common table salt (...) (Hornby-Gatenby-Wakefield: 1963).

white:1. Of the colour of milk or fresh snow, due to the reflection of all

visible rays of light; the opposite of black: a sheet of white paper (...).

(http://www.oxforddictionaries.com/definition/english/white. 15.06.2016).

Newton'un prizma deneyi ile tayfta yer almadıkları anlaşılan ve renk olmadıkları bilimsel olarak kanıtlanan kara ile $a k$, günlük hayatta ve pratikte renk olarak kabul edilir (Pastoureau 2013: 103).

\subsection{Eş anlamlısıyla tanımlanan renkler}

Eş anlamlı olarak kabul edilen bazı renk adları, karşılıklı olarak biri birleriyle tanımlanmakta; ancak, bu tür tanımlar, bazı sıkıntıları da içinde barındırmaktadır. Örneğin, bunu, kırmızı, al, kızıl renk adlarında görebiliyoruz ( $b k .4)$ :

kırmızl: Al, kizll renk.

al: Kanın rengi, kızıl, kırmızı.

kızll: Parlak kırmızı renk.

parlak: 1. parlayan, ışıldayan. 2. ..., 3. ..., 4. ...

Bu tanımlara göre, kırmızı kelimesi "al, kızıl" kelimeleri ile; al kelimesi ise "kızıl, kırmızı" kelimeleri ile açıklanmış, yani kırmızı, kızıl ve al kelimeleri eş anlamlı olarak kabul edilmiş. Ancak al kelimesinin tanımında, kırmızı ve klzllın yanına kanın rengi de eklenmiş. Kızıl ise "parlak kırmızı renk olarak tanımlanmış. Yani, al ile kırmızının tanımlarına göre al, kırmızı, kızıl eş anlamlı, kızılın tanımına göre ise, eş anlamlı değiller.

Diğer bir açıdan bu renk tanımlarını şöyle açıklayabiliriz: 


\section{ÇÜTAD}

\section{Çukurova Üniversitesi Türkoloji}

Araștırmaları Dergisi

Cilt 2, Sayı 2

Aralık 2017

Kırmızı renk, al renktir, yani kan rengidir, kızıl renktedir, yani parlak kırmızı renktir. Al renk, kan rengidir, kızıl renktir, yani parlak kırmızı renktir. Kızıl ise, parlak kırmızı renktir. Tanımda böyle bir yolun izlenmesi, eş anlamlı ya da çok yakın anlamlı kelimeleri tanımlama güçlüğünden kaynaklanmaktadır.

Ayrıca, al, kırmızı, kızıl renkleri arasında tam bir eş anlamlılık olduğunu söylemek de kolay olmasa gerek. Al bayrak, kızıl bayrak, kırmızı bayrak tamlamalarında, al ile kırmızı eş anlamlı sayılabilir mi? Silifke'nin meşhur türküsündeki, “Türkmen kızı Türkmen kızı (...)/Sen allar giy ben kırmızı", dizeleri dikkate alındığında, acaba al ile kırmızı için eş anlamlı denebilir mi?

Dilde tam anlamıla eş anlamlı olan kelimelerden birinin yaygınlaşıp diğerinin veya diğerlerinin kullanımdan düşmesi yaygın bir kural iken, eş anlamlı biçiminde tanımlanan üç kelimenin yan yana yaşaması aralarında çok ince bir anlam farkının olduğunu mu gösteriyor?

\subsection{Nesne ve bitki renkleri ile tanımlanan renkler}

Bazı renk adları, nesne ve bitki adlarından renk aktarımıyla, yani nesne ve bitki renkleriyle tanımlanır. Renkler, "leylak rengi: Leylak çiçeğinin rengi." örneğinde olduğu gibi bir nesnenin rengiyle eşleştirilerek; "gümüş rengi: Gümüş parlaklığında, gümüşü andıran renk, gümüşi”, örneğinde olduğu gibi bir rengin bir başka renge yaklaşması, bir rengin diğer bir rengi çağrıştırması biçiminde tanımlanır.

bakla çiçeği: Bakla çiçeği rengi.

boz: 1. Açık toprak rengi. 2. Kül rengi, gri.

${ }^{4}$ http://turku.sitesi.web.tr/silifke/turkmen-kizi-turkmen-kizi.html, 21.10.2017. 


\section{ÇÜTAD}

\section{Çukurova Üniversitesi Türkoloji}

Araștırmaları Dergisi

Cilt 2, Sayı 2

Aralık 2017

filiz rengi: Asma filizinin rengi, açık yeşil renk, filizi.

kül rengi: Odunun yanmasıyla oluşan külün akla kara arasındaki rengi, gri.

sincabi: Sincap rengi.

şarap rengi: kırmızı şarabın rengi.

toprak rengi: Toprağın sarl veya yeşile çalan rengi.

$\mathrm{Bu}$ tür tanımlarda, renkler biliniyorsa, nesnenin bilinmesine gerek yoktur; ancak, renk bilinmiyorsa, nesne görülmeden, nesnenin rengi hakkında fikir sahibi olmadan renk tanımı bir şey ifade etmez.

\section{renkler \\ 2.4. Bir rengin dereceleri veya tonları ile tanımlanan}

$A c ̧ ı$ ve koyu sıfatlarıyla oluşturulan renk adlarının tanımı, birbirine yakın anlatım kalıplarıyla yapılır. Bu tür tanımlamalarda, bir rengin açıklık veya koyuluk tonu kesin olarak belirlenemediği için ton derecesi, bir veya birkaç ton olarak belirtilebilir. Ayrıca, bazı renklerin koyusunun tanımı, ton yanında, bir başka renge yakınlıkla da desteklenebilmektedir.

\subsubsection{Açık ve koyu sıfatıyla tanımlanan renkler}

Açık, koyu sıfatlarıyla yapılan tanımlar, renk adının önüne $a c ̧ ı k$ veya koyu sıfatı getirilerek, açık / koyu + renk adı veya $a c ̧ ı /$ $k o y u+$ renk $a d l+$ renk biçiminde yapılır. İki renk adı arasındaki tek fark, renk adından sonra renk kelimesinin konup konmaması ile ilgilidir. Örneğin yeşil yerine yeşil renk, sarı yerine sarı renk denmesi gibi.

Burada söz konusu olan renklerin tanımı, aynı zamanda o rengin adı da olabilmektedir. Örneğin güvela, "açık yeşil”" olarak tanımlanır, ancak, açı yeşil aynı zamanda tanımlanan rengin adidir. 


\section{ÇÜTAD}

Çukurova Üniversitesi Türkoloji

Araştırmaları Dergisi

Cilt 2, Sayı 2

Aralık 2017

\subsubsection{Açık / koyu + renk adı biçimindeki tanımlar:}

$\mathrm{Bu}$ tür tanımlar, renk adından önce, açık veya koyu sıfatı getirilerek yapilır:

çakır: Açık mavi.

gökyüzü mavisi: Açık mavi.

güvela: Açık yeşil.

duman rengi: Koyu kül rengi.

gece mavisi: Koyu mavi.

okyanus mavisi: Koyu mavi.

\section{tanımlar:}

2.4.1.2. Açık/koyu + renk adı + renk biçimindeki

$\mathrm{Bu}$ tür tanımlarda, renk adı + renk, biçimindeki renk adından önce, açık veya koyu sıfatı getirilir:

eflatun: Açı mor renk.

kazayă̆ı: Açık turuncu renk.

küf rengi: Açık yeşil renk.

çivit rengi: Koyu mavi renk.

fes rengi: Koyu kırmızı renk.

kurşun grisi: Koyu gri renk.

barut rengi: Koyu gri renk.

\subsubsection{Bir rengin bir veya birkaç ton açı̆̆ı biçiminde tanımlanan renkler}

$\mathrm{Bu}$ tür tanımlar, tamlayan durumunda olan renk adı + tanımlanan rengin derecesi biçimindedir. Bu tanımlamanın yapısı da isim tamlaması biçimindedir. Anlatılmak istenen renk, ana renk 


\section{ÇÜTAD}

Çukurova Üniversitesi Türkoloji

Araştırmaları Dergisi

Cilt 2, Sayı 2

Aralık 2017

durumunda olan veya daha çok bilinen bir renkle mukayese edilerek tanımlanır. Ayrıca, bazı renklerin tanımında, bu anlatım kalıbına ek olarak, açıklayıcı ifadeler de kullanılabilir:

açık gri: Grinin bir veya birkaç ton açığı.

açık kahverengi: Kahve renginin bir veya birkaç ton açı̆̆l, sütlü kahve, kestane rengi, kestane dorusu.

açık kestane: Kestane renginin bir veya birkaç ton açı̆̆g.

açık kırmızı: Kırmızının bir veya birkaç ton açı̆̆ı.

açık mavi: Mavinin bir veya birkaç ton açı̆̆ı.

\subsubsection{Bir rengin bir veya birkaç ton koyusu biçiminde tanımlanan renkler}

$\mathrm{Bu}$ tür tanımlar, tamlayan durumunda olan renk adı + tanımlanan rengin derecesi biçimindedir. Bu tanımlamanın yapısı da isim tamlaması biçimindedir. Anlatılmak istenen, tanımlanan renk, esas alınan bir rengin bir veya birkaç ton koyusudur.

koyu mavi: Mavinin bir veya birkaç ton koyusu.

koyu sarı: Sarının bir veya birkaç ton koyusu.

koyu pembe: Pembenin bir veya birkaç ton koyusu.

\subsubsection{Bir renge yakınlıkla ve bir rengin tonuyla tanımlanan renkler}

$\mathrm{Bu}$ tanımlarda önce, yönelmeli renk adl + yakın + renk $a d \imath$ biçiminde bir tanımlama yapılır, bundan sonra bu tanımlamayı daha da netleştirmek, daha açık hâle getirmek için, tamlayan durumundaki renk adl + bir veya birkaç ton koyusu biçiminde ikinci bir tanım daha yapılır:

koyu yeşil: Siyaha yakın yeşil, yeşilin bir veya birkaç ton koyusu. ton koyusu.

koyu kırmızı: Bordoya yakın kırmızl, kırmızının bir veya birkaç 


\section{ÇÜTAD}

\section{Çukurova Üniversitesi Türkoloji}

Araștırmaları Dergisi

Cilt 2, Sayı 2

Aralık 2017

koyu lacivert: Siyaha yakın lacivert, lacivertin bir veya birkaç ton koyusu.

\subsubsection{Açık ve koyu dışındaki bazı sıfatlarla türetilen renk adlarının tanımı}

$A c ̧ ı k$ ve koyu sıfatlarının yanında, renk adı türetiminde daha seyrek kullanılan bazı sıfatlar da bulunmaktadır:

acı: Çarpıcı göz alıcı (renk).

çiğ: Gözü rahatsız eden, göze batan (renk, lşık).

donuk: Rengini ve parlaklığını kaybetmiş, mat bir biçimde.

kırık: Saf renkten hafif uzaklaşmış: Kırık beyaz.

kirli: Leke, toz, vb. ile kapl, pis, murdar, mülevves.

soluk: rengi atmış, solmuş, uçuk.

uçuk: 1. Uçmuş, soluk. 2. Açık (renk).

$\mathrm{Bu}$ sıfatlarla türetilen renk adlarının tanımları, renklerin derecelerini ve değişik özelliklerini belirtir.

TS'de, bu sıfatlardan bazılarının tanımında renklerle olan ilişki belirtilmiş, bazılarının tanımında ise belirtilmemiştir. Bunun en dikkat çekici örneğini, kirli kelimesinin tanımı ile kirli sarı arasındaki ilişkide görebiliriz. Kirli kelimesi tanımlanırken renklerle olan ilişkisi belirtilmemiştir.

kirli: Leke, toz, vb. ile kapl, pis, murdar, mülevves.

kirli sarı: Koyu ve donuk sarı renk.

TS'de, bu sifatlardan sadece $a c \imath$ ve kirli ile türetilen renk adlarına madde başı olarak yer verilmiş ve tanımları yapılmıştır. "Kırık beyaz"a ise kırık maddesi altında yer verilmiştir. Aslında kırık beyazın da madde başı olması gerekir. 


\section{ÇÜTAD}

\section{Çukurova Üniversitesi Türkoloji}

Araştırmaları Dergisi

Cilt 2, Sayı 2

Aralık 2017

$\mathrm{Bu}$ sifatlarla türetilen renk adlarının tanımı, "acı" kelimesinin "çarpıcı + göz alıcı + (renk)" biçimindeki tanımında olduğu gibi, renk bildiren sıfatın niteliği + renk bildiren sıfatın niteliğ $i$ + renk $a d \imath$ / renk biçiminde yapılmaktadır:

acı (I): Çarpıcı göz alıcı (renk).

acı yeşil: Çarpıcı göz alıcı yeşil.

kirli sart: Koyu ve donuk sart renk.

TS'de kirli sarı renk adı, hardal rengi ile kaz boku renk adlarının karşılığı, dolayısıyla eş anlamlısı olarak verilmiştir:

hardal rengi: Kirli sart renk.

kazboku: Kirli sarı renk.

$\mathrm{Bu}$ tanımlara göre, hem hardal rengi, kirli sarl renktir, hem kazboku, kirli sarı renktir. Yani, hardal rengi ile kazboku, eş anlamlıdır. Bu durumda, hardal rengine kazboku denebilir. Ancak hardal yenen bir madde olduğu için kazboku ile yan yana getirilmemiştir. rastliyoruz:

TS'de yer almayan "kirli mavi”ye ise, Attila İlhan'da

(...) yalnız Doktor Selâhattin ve Güzide Sibel Hanım değil; kirli mavi bir duman perdesi arkasindan, 'bütün meyhane' onlar seyrediyor (Ilhan 1999:172).

Bir rengin değişik görünümleri, değişik ara tonları, değişik toplumlarda, örneğin Batı, Japon, Asya, Afrika Kızılderili toplumlarında birbirinden farkl1 olarak algılanıp tanımlanabilmektedir. Örneğin, siyahi Afrika toplumlarının çoğunda, belirli bir rengin kuru, ıslak, yumuşak, sert, kaygan, pürtüklü, sağır, sesli, neşeli veya hüzünlü bir renk olup olmaması büyük önem taşır (Pastoureau 2013: 159-160). 


\section{ÇÜTAD}

Çukurova Üniversitesi Türkoloji

Araștırmaları Dergisi

Cilt 2, Sayı 2

Aralık 2017

\subsubsection{Bir rengin başka bir renge yakınlığı veya başka bir rengi hatırlatmasıyla tanımlanan renkler}

Bir rengin başka bir renge yakınlığı veya bir başka rengi hatırlatmasıyla yapılan tanımlamalar için, çalan, çalar, arasında, arasındaki, andıran, yakın, tutmuş, benzer sıfatları, kullanılır. $\mathrm{Bu}$ tanımlarda değişik anlatım kalıpları kullanılmaktadır.

\section{tanımlanan renkler \\ 2.4.6.1. Bir rengin bir başka renge çalmasıyla}

$\mathrm{Bu}$ tanımlar, "camgöbeği: Yeşile çalan mavi renk (<yeşile $\underline{+ \text { çalan }}+\underline{\text { mavi }+ \text { renk) }}$ tanımında olduğu gibi yönelmeli renk adı + çalan + renk adl + renk kelimesi biçiminde yapılmaktadır. $\mathrm{Bu}$ tür tanımlar, sıfatlığı (yeşile çalan) sıfat-fiil grubu, isim unsuru sifat tamlamasi olan bir sifat tamlamasi yapisındadır: yesile çalan + mavi renk. Yaygın olan bu tanım biçiminin yanında, toprak rengi: Toprağın sarı veya yeşile çalan rengi; limon rengi: Yeşile çalan açık sarı, limoni, vb. tanımlar da bulunmaktadır. "Çalan” ile yapılan renk tanımlarında, birinci renk, hatırlanan, çağrışan renk, ikinci renk asıl renktir. Tanımlanan rengin bir başka renge çaldığ 1 , onu çağrıştırdığ 1 , onu hatırlattığ 1 belirtilir. Anlatılmak istenen renk, bir ana renk veya daha çok bilinen bir rengin yardımıyla tanımlanır. Ayrıca, tanımlanan, bir başka renge çalan ${ }^{5}$ renk, bir rengin değişik tonlarından biridir.

TS'nin 9. baskısında (1998), çalar olarak tanımlanan bakır çalığl, camgöbeği, ela, güvela, haki, siklamen renkleri, 10. baskıdan (2005) itibaren, çalar yerine çalan; çalar ile tanımlanan siyahımtırak ise, siyahımsı olarak tanımlanmıştır.

bal rengi: Kahverengine çalan sarı renk.

5 TS'de “çalmak” eyleminin 8. anlamı “(-e) Benzemek, andırmak.” olarak verilmiş. Bu fiillerden benzemek geçişsiz, andırmak ise geçişlidir. Tanımda buna dikkat edilmesi gerekirdi, zira benzemek, “(+e) benzemek”tir, ama, andirmak, “(+e) andırmak değil, “(-i) andırmak’tır. 


\section{ÇÜTAD}

Çukurova Üniversitesi Türkoloji

Araștırmaları Dergisi

\section{Cilt 2, Sayı 2}

Aralık 2017

bakır çalığı: Yeşile çalan mavi renk.

esmer: 1. Siyaha çalan buğday rengi. 2. Kurşunî renk.

kavuniçi: Pembeye çalan sarı renk.

kimyon rengi: Kahverengine çalan yeşil renk, kimyoni.

limon küfü: Yeşile çalan mavi renk.

mor: Kırmızı ile mavinin karlşmasından oluşan renk, menekşe renginin kırmızıya çalanı.

elâ :Gözde sarlya çalan kestane rengi

güvelâ: Açık yeşil, maviye çalan göz rengi.

hâkî: Yeşile çalan toprak rengi, vb.

\subsubsection{Belirtilmeyen rengin belirtilen renge veya belirtilen rengin belirtilmeyen renge çaldığı renkler}

$\mathrm{Bu}$ tanımlar, isnat grubu veya sifatlığı sifat-fiil grubu biçiminde olan sıfat tamlaması yapısındadır. $\mathrm{Bu}$ tür tanımlar, "rengi + yönelmeli renk ad + çalan" yani "bozca: Rengi + boza + çalan" veya "yönelmeli renk ad $1+$ çalan + renk" yani "Maviye + çalan + renk" biçiminde yapılmaktadır. Örneğin, rengi boza çalan tanımında, hangi rengin boza çaldığı, maviye çalan renk tanımında ise, maviye çalan rengin hangi renk olduğu bilinmez.

bozca: Rengi boza çalan.

bozrak: Rengi boza çalan.

gökçül: Maviye çalan renk.

şekerrenk: Sarıya çalan renk.

\section{renkler \\ 2.4.6.3. Andıran ve benzeyen biçiminde tanımlanan}

Bu tanımların ana yapısı "mavimsi: Rengi maviyi andiran, maviye benzeyen, mavimtırak" örneğinde olduğu gibi, genellikle, 


\section{ÇÜTAD}

Çukurova Üniversitesi Türkoloji

Araştırmaları Dergisi

Cilt 2, Sayı 2

Aralık 2017

belirtme durumunda renk adı + andiran + yönelme durumunda renk $a d l+$ benzeyen biçimindedir. Bunların yanında, bu tür tanıma ek açıklamalar getiren veya mavimtırak: Maviyi andıran örneğinde olduğu gibi, sadece, belirtme durumunda renk adı + andıran biçiminde yapılan tanımlar da bulunmaktadır. Bazı tanımlar, + mtırak, $+m s I /+m s U$ ekleriyle türetilmiş renk adlarıyla veya bu renk adlarına renk adından sonra $+A$ benzeyen ve $+I /+U$ andiran ifadelerinin eklenmesiyle de yapilabilmektedir. $\mathrm{Bu}$ tanımlarda, tanımlanan rengin ölçü olarak alınan bir renge yakın olduğu, onu andırdığı, ona benzediği belirtilir. Tanım, bir rengin bir başka rengi andırmasına veya bir rengin bir başka renge benzemesine, onu çağrıştırmasına dayanmaktadır.

Dikkat çeken tanımlardan biri de, her iki ekin işlevleri birbirine yakın olduğu için, + mtırak, ekiyle türetilen renk adlarının $+m s I /+m s U$ ekiyle türetilen renk adıyla, $+m s I /+m s U$ ekiyle türetilen renk adlarının da +mtırak ekiyle türetilen renk adıyla tanımlanmasıdır.

lâciverdimsi: Rengi laciverdi andiran, laciverde benzeyen.

mavimsi: Rengi maviyi andıran, maviye benzeyen, mavimtırak.

pembemsi: Rengi pembeyi andiran, pembeye benzeyen, pembemtirak.

beyazımsl: Rengi beyazı andıran, beyaza benzeyen, beyaz gibi, beyazımtırak.

beyazımtırak: Beyazımsı.

siyahımtırak: Siyahımsı.

mavimtırak: Maviyi andiran.

findlkkabuğu: Findiğın kabuğunun rengini andiran bir tür kahve rengi, findik rengi. gümüşi.

gümüş rengi: gümüş parlaklığında, gümüşü andıran renk, 


\section{ÇÜTAD}

Çukurova Üniversitesi Türkoloji

Araștırmaları Dergisi

Cilt 2, Sayı 2

Aralık 2017

taba: Kuru tütün yapră̆ını andıran kızılımsı kahverengi.

\subsubsection{Bir renge yakınlığı ile tanımlanan renkler}

$\mathrm{Bu}$ renklerin tanımı, rengi + yönelmeli renk adı + yakın veya yönelmeli renk adl + yakın biçimindedir. Bu tanımın başına "rengi”, sonuna, “+A çalan”, “olan”, vb. biçiminde pekiştirici ifadeler de eklenebilmektedir.

karaca: Rengi karaya yakin olan, esmer.

pembemsi: Rengi pembeye yakın olan, pembeye çalan.

siyahımsl: Siyaha yakın.

\subsection{7. İki veya daha fazla rengin arasında olduğu belirtilerek yapılan tanımlar}

Tanım, renk adl + ile (ve) + renk adl + arasinda (arasındaki) + renk (renk adı) biçiminde yapılır. Tanımlanan renk ara renktir. Elbette tanımlanan ve iki rengin arasında bulunan ara rengin kesin tonunu söylemek de mümkün değildir.

böcek kabuğu: Mor ile yeşil arasında ve metal parlaklı̆̆ında olan renk.

güvercinboynu: Yeşil, mavi ve pembe arasında dalgalanır gibi görünen renk.

güvercingöğsü: Yeşil ile mavi arasında böcekkabuğuna benzer dalgalı ve değişken renk.

kemik rengi: Beyaz ile krem rengi arasinda olan renk.

kül rengi: Odunun yanmasıyla oluşan, külün akla kara arasındaki rengi, gri.

pas rengi: Kırmiziyla kahverengi arasindaki renk. 


\section{ÇÜTAD}

Çukurova Üniversitesi Türkoloji

Araștırmaları Dergisi

Cilt 2, Sayı 2

Aralık 2017

sarl $^{6}$ : Yeşil ile turuncu arasinda bir renk, limon kabuğu rengi.

sincap rengi: Kahverengi ile kurşun rengi arasinda olan (renk).

zeytin rengi: Koyu gri ve siyah arası bir renk.

\subsubsection{Karışımla tanımlanan renkler}

Bazı renkler, farklı renklerin karışımı olarak tanımlanır. Bu renklerin, ikili tanımları da yapılabilmektedir. Örneğin mor rengin tanımında karışım + yönelmeli renk adı + çalan biçimi birlikte kullanılmıştır (bk.2.4.4.1.).

mor: Kırmızı ile mavinin karlşmasından oluşan renk, menekşe renginin kırmızıya çalanı.

yeşil: Sarı ile mavinin karışmasından ortaya çıkan, bitki yapraklarının çoğunda görülen renk.

\subsection{Edebi metinlerdeki renk adlandırmalarının tanımı}

Şairlerin ve yazarların edebi metinlerde, anlatıma derinlik ve çağrışım zenginliği katmak için kişisel olarak kullandıkları ölçün dışı renk adlarının pek çoğunu tanımlamak zordur. Örneğin, çatal kara, zindan yeşili, çingene moru, deniz dibi yeşili, ecel yeşili, Allah mavisi, kasaturanın moru (Güngördü 2011: 21-22), çelik mavisi, ustura mavisi, firuze mavisi, damar mavisi, maytap mavisi, cam mavisi, aydinlık mavi, mine mavisi, elektrik mavisi, buz mavisi, rakı mavisi (İlhan 1999: 27, 30, 43, 43, 46, 49, 50, 75, $97,171,218), v b$. renklerin bazıları, iyimser bir yaklaşımla, yaklaşık olarak tanımlansa bile, bazılarını tanımlamak mümkün değildir. Ayrıca böyle bir tanımlamayı yapma gereği de yoktur. Okuyucu, her rengi, zihninde kendi duygu dünyasının ve hayal ufkunun çemberi içinde, gönlünce ve keyfince canlandırabilmeli.

\footnotetext{
6 “Sarı”nın tanımı, Türkçe Sözlük'ün 9. Baskısından sonraki baskılarda, değişmiştir. 9. Baskıdaki tanım: sarı: Güneş ışığının ayrışma tayfında yeşil ile portakal rengi arasında olan renk, altının rengi (Türkçe Sözlük 1998).
} 


\section{ÇÜTAD}

Çukurova Üniversitesi Türkoloji

Araştırmaları Dergisi

Cilt 2, Sayı 2

Aralık 2017

\subsection{Kişisel olarak adlandırılmış renklerin tanımı}

Ölçünlü Türkçede kullanılan renk adlarının yanında, ölçünlü Türkçede yer almayan deniz dibi yeşili, hayit yeşili, Bursa yeşili, salatallk yeşili, Ankara armudu yeşili, toprak yeşili, vb. biçimdeki renklerin (Bayraktar 2010: 188) tanımı, kolay değildir. Gerek salatalık yeşili, Ankara armudu yeşili gibi, nesne adlarıla türetilen, gerekse renklere doğrudan doğruya verilen ahududu, avokado, kayısl, vişne, safran, hanımeli, acıbadem, vb. biçimde adlandırılan renkler, birçok kişide yeterli çağrışım yapmayabilir.

Kişilerin çevrelerindeki herkesçe bilinmeyen bitki, meyve, sebze, nesne $v b$. adlarından kendilerince türettikleri renk adlarının tanımını ancak o nesneyi tanıyanlar yapabilir. Bu tür renk adının veya tanımının ölçülü Türkçeye girebilmesi için, renk adının belirli bir kullanım sıklığına, bilinirliğe ve tutarlılığa sahip olması, tanımın da buna göre yapılması gerekir. Her münferit kullanımı, renk adı, dolayısıyla dil zenginliği saymak gerekmez.

\section{tanımı}

2.7. Keyfi adlandırılan veya numaralanan renklerin

Bazı boya firmalarının renk kataloglarında veya renk kartelalarında, renkler, rakam + nesne, şehir, ülke, coğrafi biçim $a d l, \quad v b$. biçiminde gösterilmekte ve renkler keyfi olarak adlandırılmaktadır: 145 Alaçatı, 7953 alüvyon, 3653 yayla yeşili, 6669 senfonik mavi, 5576 kanyon, 2919 Göreme ${ }^{7}$. Elbette, değişik katalog ve kartelalarda, rastlayabileceğimiz Havana, firtına, fistık, Ilgaz, A ğrı, Amasra, Çayeli, kumru, kese kâğıdl, vb. biçimindeki tamamen keyfi olarak adlandirılan renkler ile 4062, 4074, 4076, 4054, 4083, 4104, 4354, 4344, 4155, 4152, 4144, 4142, 4145,

\footnotetext{
${ }^{7}$ http://www.dyo.com.tr/dyo/dekoratif-dis-cephe-renk-kartelasi, 20.10.2015
} 


\section{ÇÜTAD}

\section{Çukurova Üniversitesi Türkoloji}

Araştırmaları Dergisi

Cilt 2, Sayı 2

Aralık 2017

4164, 4161, 4166, vb. biçimde doğrudan doğruya numaralanmış renklerin tanımlarını yapabilme olanağı yoktur.

\section{YETERSIZ VEYA EKSIKK TANIMLAR}

TS'deki bazı tanımların yetersiz olduğu söylenebilir. Özellikle, nesneye bağlı tanımlarda, sadece nesne renginin söz konusu edilmesi durumunda, tanım yetersiz kalabilir.

baklaçiçeği: Bakla çiçeği rengi. bitki.

bakla çiçeği: Sarımtırak, eflatuna çalan beyaz renkte bir

TS'de, bitişik yazılan baklaçiçeği renk adı yanında, bakla çiçeği biçiminde ayrık yazılan ve bitki adı olduğu belirtilen ikinci bir kelimeye daha yer verilmiştir. Ayrık yazılan bakla çiçeği bitki değil bakla bitkisinin çiçeği olmalı. Dolayısıyla, aynı kelimenin iki ayrı yazımına ve iki ayrı tanımına yer verilmiş. Ayrıca, kelimenin "baklaçiçeği rengi: Sarımtırak, eflatuna çalan beyaz renk" biçiminde tanımlanması daha uygun olurdu.

gül rengi: 1. Gül çiçeğinin rengi. 2. Bu renkte olan.

Tanımda kastedilen gül, acaba hangi renktedir? Pembe mi, kırmızı mı, sarı mı, fes rengi mi? Aynı sorun "gülgüli: Gül renginde olan" tanımı için de geçerlidir.

toprak rengi: Toprağın sarı veya yeşile çalan rengi.

Bildiğim kadarıyla rengi sarıya çalan toprak olur da, rengi yeşile çalan toprak olmaz.

\section{turp filizi: Turp rengi.}

Filiz, "Tohumdan çıkan körpe ve küçük dal, sürgün, ışkın eşkin (II), cımbar, çıvgın, şıvgın." olduğuna göre, turp filizi rengi, yeşil ile ilgilidir. Oysa, tanımda, turp rengi demekle yetinilmiştir. Turp deyince herkesin aklına, turpun toprak içinde oluşan, kırmızı, 


\section{ÇÜTAD}

\section{Çukurova Üniversitesi Türkoloji}

Araștırmaları Dergisi

Cilt 2, Sayı 2

Aralık 2017

pembeye çalan kırmızı veya beyaz yumrusu gelir. Dolayısıyla, turp filizinin rengi yeşille, turpun rengi de koyu pembeyle, pembeye çalan kırmızıyla ilgili olarak açıklanmalıydı.

zeytunî: Zeytin rengi.

zeytin rengi: Koyu gri ve siyah arası bir renk.

Koyu gri ve siyah arası bir renk biçimindeki tanımın Koyu gri ile siyah arası bir renk olması, yani "ve" yerine "ile" kullanılmas1 daha uygun olurdu. Tanımda kastedilen zeytin renginin olgunlaşmış zeytinin rengi olduğu anlaşıllıyor. Bunu, sözlükte yer alan yeşilzeytin maddesi de göstermektedir:

yeşilzeytin: Zeytinin salamura edilmiş yeşil renkli türü.

Boya sanayisi ile ilgili renk kataloglarında, zeytin renginin yeşil zeytini gösterdiği anlaşılmaktadır. Örneğin, duvar kâğıtları kataloğunda, zeytin ${ }^{8} 6063$ adlı renk, koyu yeşil olarak gösterilmiş. Renkler skalasında ise, zeytin yeşili ${ }^{9}$, mavi + açık yeşil karışımı olarak verilmiş. Skalada, zeytin rengi, yerine zeytin yeşili denmesi, hem rengi vurgulamak hem de yeşil zeytinin rengini bilmeyenlerde bir tereddüt bırakmamak için olsa gerek. Peride Celal de Ağaç adlı öyküsünde, anlatmak istediği yeşil rengi "siyaha çalan zeytin yeşili" biçiminde tanımlar (Peride Celal, Kış, 2010, 19).

Burada karşımıza çıkan sorun, "zeytin rengi”nin, zeytin meyvesinin olgunlaşma sürecinin hangi aşamasındaki rengini karşıladığıdır.

\section{RENKLERİ TANIMLAMA GÜÇLÜĞÜ}

\footnotetext{
${ }^{8}$ http://www.duvarrenkleri.com/boya-kataloglari-tum-markalar 15.10.2015.

${ }^{9}$ http://www.unutulmussanatlar.com/2013/01/renk-skalas-renkler-ve-ozelliklerirbg_44.html, 15.010.2015
} 


\section{ÇÜTAD}

\section{Çukurova Üniversitesi Türkoloji}

Araștırmaları Dergisi

Cilt 2, Sayı 2

Aralık 2017

Birbirine çok yakın farklı renklerin tanımlarında, bazı zafiyetler olabilmektedir. Bu renklerden bazıları, adındaki nesne adı dolayısıyla tahmin edilse bile, kullanım sıklıkları düşük olan renkleri tanımlamak, kullanım sıklığ 1 yüksek olan renklere göre daha zordur (bk. 2.2).

Renk tanımlamasındaki güçlüğü, bilinen ve tanınan bir renk olan krem renginin diğer bir anlatımla açık saman sarısının ve ilgili renklerin tanımlarında görebiliriz:

krem: Açık saman rengi, krem rengi.

açık saman rengi: Soluk sarı renk.

saman rengi: Açık, soluk sarı renk, saman sarısl.

saman sarlst: Saman rengi.

krem rengi: Krem.

Tanımında "soluk sarı renk"e eklenen tamamlayıcı ifadeler bir yana bırakılırsa, saman rengi "soluk sarı renk"tir, açık saman rengi de, "soluk sarı renk"tir. Buna göre, "saman rengi"ne, "açık saman rengi" de denebilir. $\mathrm{Bu}$ tanımda, bir rengin açık rengiyle aynı renkte olması gibi, anlatım zafiyeti bulunmaktadır.

\section{SONUÇ}

Bir rengi doğrudan doğruya tanımlamak oldukça zordur. Tanımlamadaki bu zorluk, rengin her türlüsü için geçerlidir. Bu güçlügü̈ aşmak için değişik tanımlama yöntemlerine başvurulmaktadır. Türk Dil Kurumu'nun Türkçe Sözlük'ünde, renklerin tanımında başvurulan belli başlı yöntemler arasında, bir rengi, karşı1 veya eş anlamlısı ile tanımlama; bir rengi nesnelerin, bitkilerin, çiçek, yaprak veya meyvelerin rengiyle tanımlama; bir rengin açıklığı veya koyuluğu ile tanımlama, bir rengin bir veya birkaç ton açığı veya koyusu ile tanımlama, bir renge yakınlık, bir renge çalma, benzeme veya bir rengi andırma biçiminde 


\section{ÇÜTAD}

Çukurova Üniversitesi Türkoloji

Araştırmaları Dergisi

Cilt 2, Sayı 2

Aralık 2017

tanımlama; bir rengi iki rengin arasındaki yeri ile veya iki rengin karışımı ile tanımlamalar bulunmaktadır. Ölçünlü dilde yer alan renk adları yanında ölçünlü dilde ve buna bağlı olarak, sözlüklerde yer almayan binlerce rengin tanımında da farklı güçlüklerle karşılaşılmaktadır. Bu renklerin bazıları ölçünlü dildeki renklerin tanımındaki yöntemlerle tanımlanabilir; ancak, herkesçe bilinmeyen nesne ve bitki adlarından kișisel benzetmelerle türetilen renk adlarıyla, yazarların ve şairlerin duygu dünyalarını yansıtabilmek için türettikleri renk adlarını tanımlamak kolay değildir. Bunların yanında, boya sanayisinde başvurulan, keyfi adlandırmalar ve numaralandırmaları tanımlamak da mümkün değildir. Bu tür münferit ve keyfi adlandırmalar ölçünlü Türkçe içinde yer alamaz. Doğada bulunan veya boya sanayisinin ürettiği binlerce renkle bir renkten başka bir renge geçişlerdeki binlerce ara rengin tümünü tanımlama olanağımız olmadığına göre, olsa olsa bunların belirli bir kısmını tanımlayabiliriz.

\section{KAYNAKÇA}

Bayraktar, Nesrin (2014), “Türkçe Yeşil Renk Adının Biçim, Anlam ve Kavram Alanına Tarihsel Bir Bakış", Journal of Language and Linguistic Studies. 10(1): 179-193.

Güngördü, Meryem (2011), Bedri Rahmi Eyüboğlu'nun Dol Karabakır Dol Adlı Şiir Kitabındaki Renkler Üzerine Bir Inceleme, Çukurova Üniversitesi Fen-edebiyat Fakültesi Türk Dili ve Edebiyatı Bölümü, Bitirme Tezi, Adana.

Hornby, A. S.- E.V. Gatenby - H. Wakefield (1963) The Advanced Learner's Dictionary of Current English, Second Editions, London.

İlhan, Attilâ (1999), Yengecin Kıskacı, Dört Uzun Hikâye, Bilgi, Yayınevi, Ankara. 


\section{ÇÜTAD}

Çukurova Üniversitesi Türkoloji

Araștırmaları Dergisi

Cilt 2, Sayı 2

Aralık 2017

Pastoureau, Michel (2013), Mavi Bir Rengin Tarihi, Çevirici: İnci Malak Uysal, Can Sanat Yayınları, İstanbul.

Peride Celal, Türk Edebiyatından Öykü Bahçesi, [Antolojiyi] Hazırlayan: Ebru Kış, Altın Anahtar Yayınları, İstanbul, s. 18-22.

Türkçe Sözlük (1998) 9. Baskl, Türk Dil Kurumu Yayınları: 549, Ankara.

Türkçe Sözlük (2005) 10. Baskl, Türk Dil Kurumu Yayınlarl: 549, Ankara.

Türkçe Sözlük (2011) 11. Bask1, Türk Dil Kurumu Yayınları: 549, Ankara.

Zülfikar, Hamza (2014), "Renkleri Adlandırma ve Tanımlama", Türk Dili, C. CVII, S. 752, Ağustos 2014, s. 57-61.

http://www.webster-dictionary.org/definition/black. 24.05.2016.

http://www.oxforddictionaries.com/definition/english/white. 15.06.2016.

http://duvarboyasirenkleri.blogspot-com.tr/2013/06/kale-colorduvar-boyas-kartelas-katalogu.html, 03.05.2014.

http://www.duvarrenkleri.com/boya-kataloglari-tum-markalar 15.10.2015.

http://www.dyo.com.tr/dyo/dekoratif-dis-cephe-renk-kartelasi, 20.10.2015.

http://www.unutulmussanatlar.com/2013/01/renk-skalas-renklerve-ozellikleri-rbg_44.html, 15.010.2015. 